\title{
The Quality of the Articles Related to Domestic Violence in Daily Newspapers
}

\author{
Besra Taş \\ Fatih University, Istanbul, Turkey
}

\begin{abstract}
Violence is an important issue in today's social life. Although existence of violence is understandable, what kind of behaviors or treatments could be identified as "violence" is controversial. In research literature, violence refers to physical and psychological pain. Violence includes many events and concepts: psychological violence, physical violence, emotional violence, sexual violence, cultural violence, political violence, juridical violence, etc.. Until recently, in print media, the subject of "domestic violence" has seldom been touched upon. But today, almost every day, we encounter a different type of violence in print media. However, the presentation, style, and the format of the violence in the media make the issue sharper. In this respect, pictures, headlines, and texts used in media to express domestic violence can harm the positive perceptions of the readers towards family and domestic communication skills. The purpose of this study is to investigate, using survey design - a type of qualitative research methods - how the issue of domestic violence including all family members was covered in print media. For this end, the newspapers with large circulation, such as Zaman, Posta, Hürriyet, Sözcü, Sabah, Habertürk, Türkiye, Bugün, and Milliyet, have been studied through content analysis technique; the topic of "domestic violence" has been investigated in terms of frequency of publication, type of publication, source of information, author, style, and detriment/benefit. The relationship among newspapers, publication frequency, author, and style; the relationship between frequency of publication and a constructive contribution to the topic has been calculated.
\end{abstract}

Keywords: domestic violence, newspaper, family, Turkey

\section{Introduction}

Domestic violence is a serious problem in Turkey as it is in many countries. In the literature, with the concept of "violence," bodily and mental grief is referred. Besides, use of force is highlighted under the concept of domestic violence. In cases of getting things by violence and psychological and bodily forcing, the addressee is defined as the victim. The concept of violence means to force someone to do something without his will and desire. The concept of violence, at the same time, involves psychological violence, such as insulting, swearing, threatening, and humiliating (Mertens \& Pankofer, 2011, p. 15).

There are various types of violence depending on the situation. The types of violence can be sorted, such as psychological violence, physical violence, emotional violence, sexual violence, cultural violence, goal-oriented violence, direct violence, constructional violence, political violence, legal violence, and illegal violence. Besides, these types of violence are defined as high level violence (Mertens \& Pankofer, 2011, p. 16).

Child abuse in today's families is one of the most discussed phenomena. Experts categorize child abuse

Besra Taş, Ph.D., instructor, Department of Educational Sciences, Faculty of Education, Fatih University. 
under four groups: bodily and psychological abuse, mental and psychological abuse, abuse of ignoring, sexual abuse, or sexual violence abuse (Mertens \& Pankofer, 2011, p. 25).

Until recently, the issue of "domestic violence" has not been mentioned and discussed in the media. Today, however, it is impossible to see such a situation. Photos, headings, and articles related to this issue present damaged family communication to readers and audience (Hartmann, 2002).

\section{Domestic Violence and Child's Victimhood}

Martinius (1989) explained the problems of children who are exposed to violence under the heading "Psychosyndrom des misshandelten Kindes" as below:

Feeling pleasure: Children who are exposed to violence experience lack of joy and happiness more often than children who are not exposed to violence.

Low self-confidence: Children who are exposed to violence feel worthless and consider their learning capacities insufficient.

Expression: The child expresses the abuse he was exposed to.

Hyperarousal: It is the state of being always alert and nervous.

Perfectionism: Child abides by the negative experience unconditionally without any reason and tries to make no errors.

Learning and ability inadequacies: Some cognitive problems can be observed in abused children. Speech disorder can be given as an example for this. It has also been interpreted as an effort of the child experiencing learning and ability problems to attract attention (Martinius, 1989; Mertens \& Pankofer, 2011, p. 38).

Apart from these problems, parents have great responsibility in problems of conflict between siblings. Parents' taking side between siblings and giving more value to one of them can lead to hatred and violence (Steck \& Cizek, 2010, p. 176).

\section{Domestic Violence in Turkey}

According to the statistical data (2008) related to domestic violence against woman, Southeast Anatolian Region, with a percentage of $19.8 \%$, is in the lead in terms of the rate of women who are exposed to violence by their husband or a person (people) they are in relation with. The second region is Northeast Anatolian Region with a percentage of $19.2 \%$, Istanbul region with $17.7 \%$, and Middle East Anatolian Region with 17.3\% follow those regions. The region with the lowest rate of violence against women is Aegean Region with 5.3\%. In terms of age, women between 15 and 24 years old are exposed to violence most with $17.3 \%$. Women between 25 and 34 follow that age group with $12.5 \%$. It can be seen that as the age increases, the rate of exposure to violence decreases. Women aged 35-44 come third with $8.7 \%$ and women between 45 and 59 years old have the lowest percentage with 4.8\% (Turkey Statistics Institution [TÜIK], 2008).

In terms of emotional violence, North East Anatolian Region takes the lead with 35.6\%. South East Anatolian region follows it with $34.7 \%$. Later, Middle East Anatolian Region comes with $28.6 \%$. The region with the lowest emotional violence abuse is West Marmara Region with $16.6 \%$. When age groups are examined in terms of emotional abuse, it is seen that as the age increases, the level of abuse in this issue decreases. While the most abused age group is 15-24, the least abused age group is 45-59.

In terms of the number of women who are exposed to sexual abuse, North East Anatolian Region has the highest percentage with $19.4 \%$. The others are respectively Southeast Anatolian Region with $13.8 \%$ and Middle 
East Anatolian Region with $11.0 \%$. The region with the lowest rate of domestic sexual abuse against women is Aegean Region with $4.1 \%$. When age groups are examined in terms of the women exposed to sexual abuse, as we have observed in other types of abuse, the most abused age group is $15-24$ with $9.7 \%$. The least abused age group is $45-59$ with $4.6 \%$ (TÜIK, 2008).

In the same study, North East Anatolian Region takes the lead with $23.1 \%$ in terms of physical violence against women by someone else apart from the husband. South East Anatolian Region follows it with 21.8\%. West Marmara Region has the lowest rate of this kind of violence with $14.2 \%$. In terms of sexual abuse by someone else apart from the husband, South East Anatolian Region has the highest rate with $4.5 \%$, and Aegean Region has the lowest rate with $1.7 \%$. It is observed that 15 years old women who are exposed to sexual violence by someone else apart from their husband are generally abused by male relatives and foreign males. It is stated that Middle Anatolian Region has the highest rate of women abused by male relatives and women younger than 15 years old have been sexually abused. West Marmara Region has the highest rate of women who are abused by foreign males and the mostly abused age group includes females younger than 15 years old.

In terms of domestic violence, violence against women maintains its importance both in Turkey and the world. Despite many regulations, the issue of violence, which threatens human rights, evokes the existence of social problems. In the societies, in which males are prominent, violence against children and women still continues to reveal itself (Ministry of Turkey, General Directorate of Institute of Females, 2008, p. 6). Because it is regarded as a kind of discipline, violence is favored in the family and it can be undisclosed. It is widely accepted that as long as inequality against women is not solved with the legal regulations all around the world, the problem of violence against women cannot be solved totally. It is highlighted that the reason is not only being equal before the law, it is also necessary to internalize the equality as a society (Ministry of Turkey, General Directorate of Institute of Females, 2008, p. 51).

In his study, Ayan (2007) examined aggressive tendencies of children who were exposed to domestic violence and whether these aggressive tendencies change according to children's sociocultural, economical, psychological, and communicative characteristics. He found that children who were exposed to violence had a higher level of aggressive tendencies. In the same study, it was stated that there were significant differences among students' aggressive tendencies according to the number of individuals living the family and mother's attitudes. Besides, it was found that students' aggressive tendencies did not change according to many variables, such as family's origin, parents' educational level and profession, family's salary, the way decisions are made in the family, violence between mother and father, father's behaviors, parents' interest in the child, parents' knowledge about friends and letting them visit home, fear against parents, being able to share the problems with parents.

In his literature review, Kaymak (2004) highlighted experiences of anger and aggressiveness in the family. In his study, in which he examines what anger and aggressiveness mean, factors leading aggressiveness in the family and the effects of anger and aggressiveness especially on the children, Ozmen stated that most of the adults using violence have a story in which they were exposed to domestic violence when they were child (Kaymak, 2004, pp. 27-39).

\section{Publication Policies of Turkish Association of Journalists (TAJ)}

TAJ (2014) stated that the first basic rule of journalists' duties and policies is to respect the realities and truth and to abide by them. In addition, it is stated in the third article of basic duties and principles that "a 
journalist has to respect universal values of humanity especially peace, democracy and human rights, plurivocality and differences." Besides, it is stated that "a journalist cannot make any news which justifies, stimulates and incites any kind of violence."

In the same list of basic duties and principles, it is highlighted in the 4th article that while giving information about the source of the news, a journalist has to know the source of the news if he reports the news. It is underlined that if the source of the news is unknown, the journalist has to report this to the public. Besides, in the 10th article, areas that a journalist has to avoid are stated. Journalists are suggested to avoid from plagiarization, slander, insult, defaming, distorting, manipulation, rumor, gossip, and baseless allegations. Moreover, in the section of referencing, it is stated that if a journalist uses information from other sources, such as news agencies and his colleagues, he has to state this citation (TAJ, 2014). In the section of journalists' proper behaviors, these statements related to children are presented, "In the crimes and sexual abuses about children, whether they be defendant, witness or victim, the pictures and names of the ones younger than 18 years old should not be broadcast. In the cases, which may affect the child's personality and behaviors, a journalist should not try to interview with children and to take their photos without getting permission from parents or other people responsible for the them" (TAJ, 2014). For the type of the news, the actuality of photos and videos should be stated clearly.

After the explanations mentioned, questions below are the problems of the study:

1. How often is the news of domestic violence included in newspapers?

2. What is the quality of the news in terms of their topic?

3. What are the contents of the news?

4. Which sources is the given information mostly based on?

5. Do the writers of the newspapers giving place to domestic violence change in terms of their identity?

6. Is there any relationship between the violence and the reason behind violence?

7. Does the quality of broadcasting change according to the type of the source? From which type does this effect stem?

8. Does the type of violence have an effect on variation of the news location?

9. Is there any relationship between the type and location of the news?

10. How effective is the type of the news to present it in the headline?

11. Is there any relationship between newspapers and violence types?

12. Does writers' variation have an effect on the headline's being negative or positive? Which type of writer leads to this difference?

\section{Method}

\section{Design of the Study}

In this study, screening method, which is one of the descriptive methods, was used. In the cases, in which the data cannot be acquired directly through observation, screening model analyzes the written materials involving the concepts and facts mentioned in the study. In this study, firstly, content analysis was conducted, and concepts and relationships which could interpret the acquired data (Yıldırım \& Şimşek, 2011) were reached.

There are four main processes in this study: coding the data, finding the themes, arranging the themes found, and interpreting the findings. 


\section{Population and Sample}

In this study, daily articles which were broadcast for one month between December 4, 2014 and December 5, 2014 in newspapers, suac as Zaman, Posta, Hürriyet, Sözcü, Sabah, Habertürk, Türkiye, Bugün, and Milliyet, were examined and how often and in what quality these articles included domestic violence was analyzed through content analysis. Within the scope of this study, based on the domestic violence regarding all family members, violence news, which occurred both between parents and among other family members, was investigated. Therefore, the sample of the study consists of one-month publications of the newspapers listed above.

\section{Data Analysis}

Coding the data. News related to domestic violence in newspapers was examined and they were grouped under some categories. These sections were coded with a few words. The data were tested many times with the help of the codes. Non-functional codes were changed and examined under more appropriate sections. When needed, new codes were produced.

Finding the themes. In this step, based on the codes, themes which could help explain the data on a general level and group it under specific categories were formed.

Organizing the themes. In this step, firstly, the data, acquired as a result of detailed and thematic coding, were organized and a system was formed. For the last step, the data acquired according to this system were reorganized and defined according to some factors.

Interpreting the findings. In this step, findings which were defined and presented in detail were interpreted and the results were introduced. As a requirement of qualitative study, the collected data had a meaning in this last step. The relationships among the acquired findings were explained, cause and effect relations were established, and explanations related to the importance the results were presented.

\section{Findings and Interpretation}

In this study, how often domestic violence was mentioned in the news, which were published in Turkish newspapers with the largest circulation (Zaman, Posta, Hürriyet, Sözcü, Sabah, Habertürk, Türkiye, Bugün, and Milliyet) between December 4, 2014 and December 5, 2014 and the quality of this news was examined through content analysis. The data below were acquired.

\section{Statistical Data Related to Domestic Violence in Newspapers}

In Table 1, the number of the news $(f)$ related to domestic violence in the newspapers $(N=352)$ examined in one month period and the percentage distributions of this news (\%) were given.

As it can be seen in Table 1, 352 news were made in total. Milliyet has the highest number of news related to domestic violence $(f=68 ; 19.3 \%)$, Türkiye newspaper $(f=50 ; 14.2 \%)$, and Hurriyet newspaper $(f=44$; $12.5 \%)$ follow it. Among the nine newspapers, Zaman newspaper $(f=25 ; 7.1 \%)$ has the lowest number of news about domestic violence.

It can be seen in Table 2, the article type with the highest percentage is "news" ( $f=287 ; 81.5 \%)$, "interview" has the second highest percentage $(f=18 ; 5.1 \%)$, "scientific comment" ( $f=17 ; 4.8 \%)$ follows it. "Announcement" ( $f=12 ; 3.4 \%)$ and "others" $(f=4 ; 1.1 \%)$ have the lowest percentages. It is remarkable here that "scientific comment" ( $f=17 ; 4.8 \%$ ) has the third highest rate. However, it is important to have informative scientific comments for the news related to domestic violence. 
Table 1

The Number of Contents Related to Domestic Violence in Newspapers

\begin{tabular}{lcc}
\hline Name of the newspaper & $F$ & $\%$ \\
\hline Milliyet & 68 & 19.3 \\
Türkiye & 50 & 14.2 \\
Hürriyet & 44 & 12.5 \\
Posta & 39 & 11.1 \\
Bugün & 37 & 10.5 \\
Sabah & 32 & 9.1 \\
Haber Türk & 30 & 8.5 \\
Sözcü & 27 & 7.7 \\
Zaman & 25 & 7.1 \\
\hline Total & 352 & 100.0 \\
\hline
\end{tabular}

Table 2

The Content Type of Articles related to Domestic Violence

\begin{tabular}{lrr}
\hline Content type & $F$ & $\%$ \\
\hline News & 287 & 81.5 \\
Column & 14 & 4.0 \\
Scientific comment & 17 & 4.8 \\
Interview & 18 & 5.1 \\
Announcement & 12 & 3.4 \\
Others & 4 & 1.1 \\
\hline Total & 352 & 100 \\
\hline
\end{tabular}

Table 3

Reasons of Domestic Violence in Newspaper Articles

\begin{tabular}{lrc}
\hline Reasons of violence & $F$ & $\%$ \\
\hline Other & 179 & 50.9 \\
Mental problems & 42 & 11.9 \\
Emotional & 42 & 11.9 \\
Economic reasons & 39 & 11.1 \\
Addictedness & 13 & 3.7 \\
Sexual & 13 & 3.7 \\
Social environment & 5 & 1.4 \\
Tradition, lack of education & 3 & 0.9 \\
Faith and technology addictedness & 2 & 0.6 \\
Total & 352 & 100.0 \\
\hline
\end{tabular}

As it can be seen in Table 3, the highest rate among the domestic violence reasons belongs to category of "others" ( $f=179 ; 50.9 \%)$, "mental problems" $(f=42 ; 11.9 \%)$, and "emotional problems" $(f=42 ; 11.9 \%)$ follow "others." "Economic problems" ( $f=39 ; 11.1 \%)$ have the third highest rate. The lowest rate belongs to the category of "faith and technology addictedness" $(f=2 ; 0.6 \%)$. Here, "mental problems" $(f=42 ; 11.9 \%)$ and "emotional problems" ( $f=42 ; 11.9 \%)$ are remarkable to discuss. It can be seen that it is necessary to help people as a society about this issue. The fact that "economic reasons" $(f=39 ; 11.1 \%)$ have the third highest rate shows that some regulations need to be made about this problem. Besides, it is important to state that in contrary with general view, "faith and technology addictedness" ( $f=2 ; 0.6 \%)$ is not stated be a significant 
problem. Results of the given articles show that the reasons of domestic violence are not explained by most of the society. As it can be seen in Table 2, the category of "others" $(f=179 ; 50.9 \%)$ has the highest percentage. This can be attributed to the fact that our society prefer to keep their problems secret. Besides, it is also remarkable that "mental problems" $(f=42 ; 11.9 \%)$ and "emotional problems" $(f=42 ; 11.9 \%)$ have the second highest percentages.

As it can be seen in Table 4, "physical violence" ( $f=281 ; 79.8 \%)$ has the highest rate among violence types. The second highest rate belongs to the category of "none" $(f=23 ; 6.5 \%)$. The lowest rate belongs to the category of "legal violence" ( $f=2 ; 0.6 \%)$. Besides, the high percentage of "physical violence" $(f=281 ; 79.8 \%)$ in Table 4 is remarkable. It is seen that physical violence is the most prevalent violence. Moreover, it can be seen that people avoid specifying the type of violence, because the categories of "none" $(f=23 ; 6.5 \%)$ and "other" $(f=19.5 ; 4 \%)$ have the second and third highest percentage respectively.

Table 4

Type of Violence in the News Related to Domestic Violence

\begin{tabular}{lrr}
\hline Type of violence & $F$ & $\%$ \\
\hline Physical & 281 & 79.8 \\
None & 23 & 6.5 \\
Other & 19 & 5.4 \\
Psychological & 10 & 2.8 \\
Legal & 2 & 0.6 \\
\hline Total & 352 & 100 \\
\hline
\end{tabular}

As it can be seen in Table 5, the highest rate of news has been made in the category of "explanation" $(f=$ $188 ; 53.4 \%)$. The category of "informing" $(f=124 ; 35.2 \%)$ follows it and the category of "comment" $(f=10$; $2.8 \%)$ has the third highest rate. According to Table 5, the categories of "rejection" $(f=1 ; 0.3 \%)$ and "reply" $(f$ $=1 ; 0.3 \%$ ) have the lowest rates.

Table 5

The Quality of the Articles About Domestic Violence

\begin{tabular}{lrc}
\hline Quality of the article & $F$ & $\%$ \\
\hline Explanation & 188 & 53.4 \\
Informing & 124 & 35.2 \\
Comment & 10 & 2.8 \\
Criticize & 8 & 2.3 \\
Expectation & 5 & 1.4 \\
Fear & 4 & 1.1 \\
Pretension & 2 & 0.6 \\
Rejection, fabrication, reply & 1 & 0.3 \\
Total & 352 & 100 \\
\hline
\end{tabular}

As it can be seen in Table 6 , most of the news has been presented "directly" ( $f=258 ; 73.3 \%)$ in the newspapers. It can be seen that "indirect reporting" ( $f=94 ; 26.7 \%)$ has been used less often than direct reporting.

As it can be seen in Table 7, the category of "agent" $(f=136 ; 38.6 \%)$ has the highest rate as the source of information. "Unknown" $(f=108 ; 30.7 \%)$ sources follow it. It is remarkable that the number of the "unknown" 
sources is rather high. This high number of unknown sources for the news related to domestic violence is a serious problem. It contradicts with the statement in the 4th article of TAJ, which gives information about the source of news. However, it is highlighted that if the source is unknown, the reporter has to notify this to the public. "Reporter" $(f=31 ; 8.8 \%)$ has the highest third rate for the source of information and the category of "expert" $(f=15 ; 4.3 \%)$ follows it. However, this kind of serious news should be resourced by an expert rather than a reporter. Another interesting point is that "shelter" $(f=1 ; 0.3 \%)$ has the lowest rate for the source of information. If the number of the news sourced from shelters was higher, this could help us understand the incidents occurring in shelters.

Table 6

The Way News Presented in the Newspapers

\begin{tabular}{lcc}
\hline Style of presentation of the news & $f$ & $\%$ \\
\hline Directly & 258 & 73.3 \\
Indirectly & 94 & 26.7 \\
\hline Total & 352 & 100 \\
\hline
\end{tabular}

Table 7

Sources of the Information in the News

\begin{tabular}{lrr}
\hline Source of the news & $F$ & $\%$ \\
\hline Agent & 136 & 38.6 \\
Unknown & 108 & 30.7 \\
News reporter & 31 & 8.8 \\
Expert & 15 & 4.3 \\
Police, news from news & 11 & 3.1 \\
Ministry & 10 & 2.8 \\
Other institutions & 9 & 2.6 \\
Relatives & 6 & 1.7 \\
Environment & 5 & 1.4 \\
Mother & 4 & 1.1 \\
Father & 3 & 0.9 \\
Child & 2 & 0.6 \\
Children's shelter & 1 & 0.3 \\
\hline Total & 352 & 100.0 \\
\hline
\end{tabular}

Table 8

The Location of the News

\begin{tabular}{lrr}
\hline Location of the news & $F$ & $\%$ \\
\hline Middle & 114 & 32.4 \\
Underside & 78 & 22.2 \\
Upperside & 71 & 20.2 \\
Others & 46 & 13.1 \\
Headline & 32 & 9.1 \\
Subheading & 11 & 3.1 \\
\hline Total & 352 & 100.0 \\
\hline
\end{tabular}

According to Table 8 , it can be seen that articles related to domestic violence are generally placed on the middle pages $(f=155 ; 58.5 \%)$. The underside pages $(f=78.22 ; 62 \%)$ has the second highest rate in terms of location of the news in the newspaper. Upperside pages $(f=71 ; 20.2 \%)$ follow them. The categories of "others" 
$(f=46 ; 13.1 \%)$, "headline" ( $f=32 ; 9.1 \%)$, and "subheadings" $(f=11 ; 3.1 \%)$ have the lowest rates, which shows that this problem is not highlighted markedly in Turkish printed media.

As it can be seen in Table 9, the category of "reporter" $(f=165 ; 46.9 \%)$ has the highest rate. The category of "others" ( $f=154 ; 43.8 \%)$ has the second highest rate. "Columnists" $(f=19.5 ; 4 \%)$ and "practitioner specialists" $(f=6 ; 1.7 \%)$ follow those categories. It is remarkable that the category of "scientists" $(f=1 ; 0.4 \%)$ has the lowest rate. However, it is important for this kind of incidents, which are dealt by experts, to be published in newspapers.

Table 9

Writers of the Articles Related to Domestic Violence

\begin{tabular}{lrr}
\hline Writer of the news & $F$ & $\%$ \\
\hline Reporter & 165 & 46.9 \\
Others & 154 & 43.8 \\
Columnist & 19 & 5.4 \\
Practitioner specialist & 6 & 1.7 \\
Lawyer & 3 & 0.9 \\
Attendant of Civil Society Organization, Himself & 2 & 0.6 \\
Scientist & 1 & 0.4 \\
\hline Total & 352 & 100.0 \\
\hline
\end{tabular}

As it can be seen in Table 10, it is a serious problem that the headings have been given mostly in a neutral way $(f=167 ; 52.2 \%)$ and this kind of news has not created a negative perception in the society. Negative quality $(f=114 ; 32.5 \%)$ has the second highest rate and positive quality $(f=71 ; 20.2 \%)$ has the lowest mean.

Table 10

The Quality of the Headings of the News Related to Domestic Violence

\begin{tabular}{lcc}
\hline The quality of the headings & $F$ & $\%$ \\
\hline Neutral & 167 & 52.2 \\
Negative & 114 & 32.5 \\
Positive & 71 & 20.2 \\
\hline Total & 352 & 100 \\
\hline
\end{tabular}

Table 11

The Subject Focus of the News Related to Domestic Violence

\begin{tabular}{lrr}
\hline Subject focus of the news & $F$ & $\%$ \\
\hline Criminal & 159 & 45.2 \\
Violence & 124 & 35.2 \\
Social problem & 23 & 6.5 \\
Legal & 19 & 5.4 \\
Others & 19 & 5.4 \\
Sheltering & 5 & 1.4 \\
Scientific & 3 & 0.9 \\
\hline Total & 352 & 100.0 \\
\hline
\end{tabular}

As it can be seen in Table 11, the category of "criminal" $(f=159 ; 45.2 \%)$ has the highest rate among the subject focuses. The category of "violence" $(f=124 ; 35.2 \%)$ has the second highest rate and the category of "social problem" $(f=23 ; 6.5 \%)$ has the third highest rate. The category of "scientific" $(f=3 ; 0.9 \%)$ has the lowest rate. 
As it can be seen in Table 12, the category of "local" ( $f=331 ; 94.0 \%)$ has the highest rate in terms of the place of violence. The categories of "outside" $(f=17 ; 4.8 \%)$ and "mixed" $(f=4 ; 1.1 \%)$ follow the category of "local."

Table 12

The Place Where Violence Related to Domestic Violence Occurred

\begin{tabular}{lrc}
\hline Place where domestic violence occurred & \multicolumn{1}{c}{$\%$} \\
\hline Local & 331 & 94.0 \\
Outside & 17 & 4.8 \\
Mixed & 4 & 1.1 \\
\hline Total & 352 & 100 \\
\hline
\end{tabular}

The correlation between violence and reasons of violence is positive and statistically significant. However, this correlation is weak. Reasons can explain $15 \%$ of the violence $(r=0.148)$. As the reasons of violence increase, the level of violence also increases, though weakly (see Table 13).

Table 13

Correlational Relationship Between the Violence and Its Reasons

\begin{tabular}{lll}
\hline & Violence & Reasons of violence \\
\hline Violence & 1.00 & $0.148^{* *}$ \\
Reasons of violence & $0.148^{* *}$ & 1.00 \\
\hline
\end{tabular}

Notes. ${ }^{*} p<0.05 ;{ }^{* *} p<0.01$.

Another example is given in the following: There is not a statistically significant relationship between the newspaper and reasons of violence $(p=0.112>0.05)$. If the relationship was significant, it would be very weak $(r=0.085)$.

In Table 13, the cross tabulation of violence and reasons of violence is given. In Table 13, analysis of sub-categories of two variables between which there is a statistically significant relationship is presented.

With the comparisons between reasons of violence and violence, the physical type of violence and reasons behind are investigated (see Table 14). Out of 352 observations, 28 stem from physical violence. In the total amount of violence, physical violence has the highest percentage of $79.8 \%$. The number of physical violence related to economic reasons is 35 , and its percentage within the violence is $12.5 \%$; it takes the lead with $89.7 \%$ among the reasons of violence related economic reasons. The number of violence related to addictedness is 11 , its percentage within the violence is $3.9 \%$ and it has the highest percentage of $84.6 \%$ among the reasons related to addictedness. The number of physical violence related to sexuality is five, its percentage within the violence is $1.8 \%$ and it has the second highest percentage with $38 . \%$ among the reasons of violence related to sexuality. The number physical violence related to emotional reasons is 36 , its percentage within the violence is $12.8 \%$ and it has the highest percentage with $85.7 \%$ among the reasons of violence related to emotional reasons. The number of physical violence related to faith is two, its percentage within the violence is $12.5 \%$ and it has the highest percentage with $100 \%$ among the reasons of violence related to faith. The number of physical violence related to parents' oppression is six, its percentage within the violence is $2.1 \%$ and it has the highest percentage of $66.7 \%$ among the reasons related to parents' oppression. The number of physical violence related to traditions is three, its percentage within the violence is $1.1 \%$ and it covers all of the reasons among the reasons related to tradition with $100 \%$. The number of violence related to social environment is four, its percentage within the violence is $1.4 \%$ and it has the highest percentage with $80 \%$ among the reasons of violence related 
social environment. The number of the physical violence related to technology addictedness is one, its percentage within the violence is $0.4 \%$ and it has a rate of $50 \%$ among the reasons of violence related to technology addictedness. The number of violence related to the lack of education is three, its percentage within the violence is $1.1 \%$ and it has a rate of $100 \%$ among the reasons of the violence related to the lack of education. The number of physical violence related to mental problems 39 , its percentage within the violence is $13.9 \%$ and it has the highest percentage with $92.9 \%$ among the reasons of violence related to mental problems. The number of physical violence is 136 , its percentage within the violence is $48.4 \%$ and it has the highest percentage with $76.0 \%$ among the other reasons of violence. Besides, the category "other reasons" related to physical violence has the highest percentage with $38.6 \%$ among the reasons of violence which are physical.

Besides, the relationship between these two variables is analyzed with Chi-square test and no relationship was found.

Table 14

Cross Tabulation Between Violence and Reasons of Violence

\begin{tabular}{|c|c|c|c|c|c|c|c|c|c|c|c|c|c|c|c|}
\hline & & & \multicolumn{12}{|c|}{ Reasons of violence } & \multirow[b]{2}{*}{ हేँّ } \\
\hline & & & 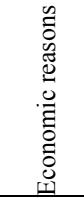 & 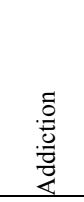 & $\begin{array}{l}\overrightarrow{\tilde{J}} \\
\overrightarrow{\mathrm{J}} \\
\text { W }\end{array}$ & 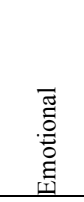 & 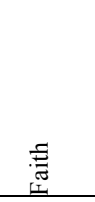 & 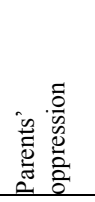 & 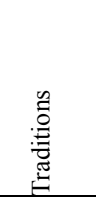 & 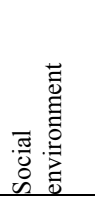 & 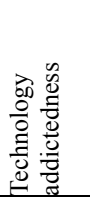 & 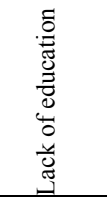 & 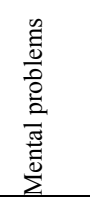 & 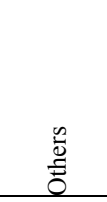 & \\
\hline \multirow{12}{*}{$\begin{array}{l}\frac{\mathscr{U}}{0} \\
\frac{0}{0} \\
\vdots\end{array}$} & \multirow{4}{*}{ 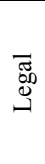 } & Number & 0 & 0 & 0 & 1 & 0 & 0 & 0 & 0 & 0 & 0 & 0 & 1 & 2 \\
\hline & & Violence (\%) & $0.0 \%$ & $0.0 \%$ & $0.0 \%$ & $50.0 \%$ & $0.0 \%$ & $0.0 \%$ & $0.0 \%$ & $0.0 \%$ & $0.0 \%$ & $0.0 \%$ & $0.0 \%$ & $50.0 \%$ & $100 \%$ \\
\hline & & Reasons (\%) & $0.0 \%$ & $0.0 \%$ & $0.0 \%$ & $2.4 \%$ & $0.0 \%$ & $0.0 \%$ & $0.0 \%$ & $0.0 \%$ & $0.0 \%$ & $0.0 \%$ & $0.0 \%$ & $0.6 \%$ & $0.6 \%$ \\
\hline & & Total (\%) & $0.0 \%$ & $0.0 \%$ & $0.0 \%$ & $0.3 \%$ & $0.0 \%$ & $0.0 \%$ & $0.0 \%$ & $0.0 \%$ & $0.0 \%$ & $0.0 \%$ & $0.0 \%$ & $0.3 \%$ & $0.6 \%$ \\
\hline & \multirow{4}{*}{ 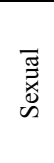 } & Number & 0 & 0 & 7 & 2 & 0 & 1 & 0 & 0 & 0 & 0 & 1 & 6 & 17 \\
\hline & & Violence $(\%)$ & $0.0 \%$ & $0.0 \%$ & $41.2 \%$ & $11.8 \%$ & $0.0 \%$ & $5.9 \%$ & $0.0 \%$ & $0.0 \%$ & $0.0 \%$ & $0.0 \%$ & $5.9 \%$ & $35.3 \%$ & $100 \%$ \\
\hline & & Reasons (\%) & $0.0 \%$ & $0.0 \%$ & $53.8 \%$ & $4.8 \%$ & $0.0 \%$ & $11.1 \%$ & $0.0 \%$ & $0.0 \%$ & $0.0 \%$ & $0.0 \%$ & $2.4 \%$ & $3.4 \%$ & $4.8 \%$ \\
\hline & & Total (\%) & $0.0 \%$ & $0.0 \%$ & $2.0 \%$ & $0.6 \%$ & $0.0 \%$ & $0.3 \%$ & $0.0 \%$ & $0.0 \%$ & $0.0 \%$ & $0.0 \%$ & $0.3 \%$ & $1.7 \%$ & $4.8 \%$ \\
\hline & \multirow{4}{*}{$\begin{array}{l}\bar{ల} \\
\frac{.0}{60} \\
\frac{0}{0} \\
\frac{0}{0} \\
0 \\
0 \\
0\end{array}$} & Number & 0 & 1 & 0 & 3 & 0 & 2 & 0 & 0 & 0 & 0 & 1 & 3 & 10 \\
\hline & & Violence (\%) & $0.0 \%$ & $10.0 \%$ & $0.0 \%$ & $30.0 \%$ & $0.0 \%$ & $20.0 \%$ & $0.0 \%$ & $0.0 \%$ & $0.0 \%$ & $0.0 \%$ & $10.0 \%$ & $30.0 \%$ & $100 \%$ \\
\hline & & Reasons (\%) & $0.0 \%$ & $7.7 \%$ & $0.0 \%$ & $7.1 \%$ & $0.0 \%$ & $22.2 \%$ & $0.0 \%$ & $0.0 \%$ & $0.0 \%$ & $0.0 \%$ & $2.4 \%$ & $1.7 \%$ & $2.8 \%$ \\
\hline & & Total (\%) & $0.0 \%$ & $0.3 \%$ & $0.0 \%$ & $0.9 \%$ & $0.0 \%$ & $0.6 \%$ & $0.0 \%$ & $0.0 \%$ & $0.0 \%$ & $0.0 \%$ & $0.3 \%$ & $0.9 \%$ & $2.8 \%$ \\
\hline & \multirow{4}{*}{ 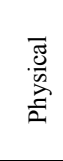 } & Number & 35 & 11 & 5 & 36 & 2 & 6 & 3 & 4 & 1 & 3 & 39 & 136 & 281 \\
\hline & & Violence $(\%)$ & $12.5 \%$ & $3.9 \%$ & $1.8 \%$ & $12.8 \%$ & $0.7 \%$ & $2.1 \%$ & $1.1 \%$ & $1.4 \%$ & $0.4 \%$ & $1.1 \%$ & $13.9 \%$ & $48.4 \%$ & $100 \%$ \\
\hline & & Reasons (\%) & $89.7 \%$ & $84.6 \%$ & $38.5 \%$ & $85.7 \%$ & $100 \%$ & $66.7 \%$ & $100 \%$ & $80.0 \%$ & $50.0 \%$ & $100.0 \%$ & $92.9 \%$ & $76.0 \%$ & $79.8 \%$ \\
\hline & & Total (\%) & $9.9 \%$ & $3.1 \%$ & $1.4 \%$ & $10.2 \%$ & $0.6 \%$ & $1.7 \%$ & $0.9 \%$ & $1.1 \%$ & $0.3 \%$ & $0.9 \%$ & $11.1 \%$ & $38.6 \%$ & $79.8 \%$ \\
\hline & \multirow{4}{*}{$\begin{array}{l}\stackrel{0}{0} \\
\stackrel{2}{2}\end{array}$} & Number & 3 & 1 & 1 & 0 & 0 & 0 & 0 & 0 & 1 & 0 & 0 & 17 & 23 \\
\hline & & Violence (\%) & $13.0 \%$ & $4.3 \%$ & $4.3 \%$ & $0.0 \%$ & $0.0 \%$ & $0.0 \%$ & $0.0 \%$ & $0.0 \%$ & $4.3 \%$ & $0.0 \%$ & $0.0 \%$ & $73.9 \%$ & $100 \%$ \\
\hline & & Reasons (\%) & $7.7 \%$ & $7.7 \%$ & $7.7 \%$ & $0.0 \%$ & $0.0 \%$ & $0.0 \%$ & $0.0 \%$ & $0.0 \%$ & $50.0 \%$ & $0.0 \%$ & $0.0 \%$ & $9.5 \%$ & $6.5 \%$ \\
\hline & & Total (\%) & $0.9 \%$ & $0.3 \%$ & $0.3 \%$ & $0.0 \%$ & $0.0 \%$ & $0.0 \%$ & $0.0 \%$ & $0.0 \%$ & $0.3 \%$ & $0.0 \%$ & $0.0 \%$ & $4.8 \%$ & $6.5 \%$ \\
\hline & \multirow{4}{*}{$\begin{array}{l}\bar{\Xi} \\
\bar{\Xi}\end{array}$} & Number & 1 & 0 & 0 & 0 & 0 & 0 & 0 & 1 & 0 & 0 & 1 & 16 & 19 \\
\hline & & Violence $(\%)$ & $5.3 \%$ & $0.0 \%$ & $0.0 \%$ & $0.0 \%$ & $0.0 \%$ & $0.0 \%$ & $0.0 \%$ & $5.3 \%$ & $0.0 \%$ & $0.0 \%$ & $5.3 \%$ & $84.2 \%$ & $100 \%$ \\
\hline & & Reasons (\%) & $2.6 \%$ & $0.0 \%$ & $0.0 \%$ & $0.0 \%$ & $0.0 \%$ & $0.0 \%$ & $0.0 \%$ & $20.0 \%$ & $0.0 \%$ & $0.0 \%$ & $2.4 \%$ & $8.9 \%$ & $5.4 \%$ \\
\hline & & Total (\%) & $0.3 \%$ & $0.0 \%$ & $0.0 \%$ & $0.0 \%$ & $0.0 \%$ & $0.0 \%$ & $0.0 \%$ & $0.3 \%$ & $0.0 \%$ & $0.0 \%$ & $0.3 \%$ & $4.5 \%$ & $5.4 \%$ \\
\hline \multirow{3}{*}{\multicolumn{2}{|c|}{ Total }} & Number & 39 & 13 & 13 & 42 & 2 & 9 & 3 & 5 & 2 & 3 & 42 & 179 & 352 \\
\hline & & Violence (\%) & $11.1 \%$ & $3.7 \%$ & $3.7 \%$ & $11.9 \%$ & $0.6 \%$ & $2.6 \%$ & $0.9 \%$ & $1.4 \%$ & $0.6 \%$ & $0.9 \%$ & $11.9 \%$ & $50.9 \%$ & $100 \%$ \\
\hline & & Total (\%) & $11.1 \%$ & $3.7 \%$ & $3.7 \%$ & $11.9 \%$ & $0.6 \%$ & $2.6 \%$ & $0.9 \%$ & $1.4 \%$ & $0.6 \%$ & $0.9 \%$ & $11.9 \%$ & $50.9 \%$ & $100 \%$ \\
\hline
\end{tabular}

Null hypothesis stating that there is no relationship between violence and reasons of violence is rejected. As it can be seen in Table 15, when the violence and reasons of violence in the articles are compared, $\mathrm{H}_{0}$ is 
rejected based on the values $X^{2}=124.954$ and $p<0.05$. Therefore, it is concluded that there is a statistically significant relationship between these two variables.

Table 15

Chi-Square Test Between Violence and Reasons of Violence $(N=352)$

\begin{tabular}{llll}
\hline Violence and reasons & Value & $S D$ & $p$-value \\
\hline Pearson Chi-square & 124.954 & 60 & 0.000 \\
\hline
\end{tabular}

According to Chi-square test, there is a relationship between the quality and the source. The percentages of this relationship are given for different sub-categories. As it can be seen in Table 16, different types of sources can change according to different qualities. Explanation (53.4\%), informing (35.2\%), commentary (2.8\%), and criticize and support (2.3\%) have the highest percentages respectively within the quality. It is remarkable here that especially categories of explanation and informing constitute $90 \%$ of the quality. Besides, the important percentages related to the sources are: agencies (38\%), unknown sources $(30.7 \%)$, news reporter $(8.8 \%)$, and specialist (4.3\%). Sub-categories stated under the sources can explain $80 \%$ of the sources. It can be seen that the explanation is affected from mostly agencies (32.1\%). Besides, unknown sources affect the explanations at the rate of $13.1 \%$. Specialists do not have almost any effect on explanations $(0.3 \%)$. Unknown sources (14.8\%), news reporter $(5.4 \%)$, agencies $(4.5 \%)$, ministry $(2.6 \%)$, and specialists $(2.0 \%)$ have an effect on informing respectively. Sub-categories of the sources affecting commentary are: specialists $(1.7 \%)$, unknown $(0.6 \%)$, ministry $(0.3 \%)$, and police department $(0.3 \%)$. The main effects are presented here and all of the mutual interactions are given in Table 16.

Table 16

Contingency Table Between the Source and the Quality of the News

\begin{tabular}{|c|c|c|c|c|c|c|c|c|c|c|c|c|c|c|}
\hline & & & \multicolumn{11}{|c|}{ Quality } & \multirow[b]{2}{*}{ Total } \\
\hline & & & 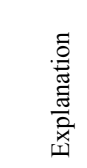 & 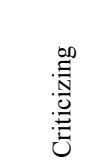 & 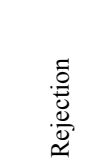 & 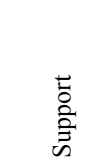 & 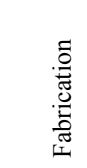 & $\begin{array}{l}\stackrel{\infty}{\Xi} \\
\stackrel{\Xi}{\Xi} \\
\stackrel{\mathscr{E}}{\Xi}\end{array}$ & 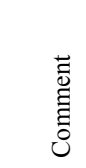 & $\frac{\lambda}{\frac{2}{2}}$ & 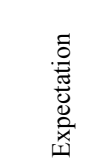 & 苛 & 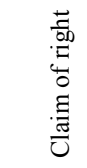 & \\
\hline \multirow{16}{*}{ 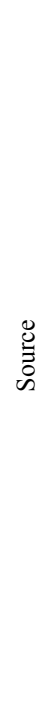 } & \multirow{4}{*}{ 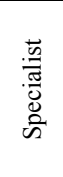 } & Number & 1 & 0 & 0 & 0 & 0 & 7 & 6 & 0 & 1 & 0 & 0 & 15 \\
\hline & & Source (\%) & $6.7 \%$ & $0.0 \%$ & $0.0 \%$ & $0.0 \%$ & $0.0 \%$ & $46.7 \%$ & $40.0 \%$ & $0.0 \%$ & $6.7 \%$ & $0.0 \%$ & $0.0 \%$ & $100.0 \%$ \\
\hline & & Quality (\%) & $0.5 \%$ & $0.0 \%$ & $0.0 \%$ & $0.0 \%$ & $0.0 \%$ & $5.6 \%$ & $60.0 \%$ & $0.0 \%$ & $20.0 \%$ & $0.0 \%$ & $0.0 \%$ & $4.3 \%$ \\
\hline & & Total (\%) & $0.3 \%$ & $0.0 \%$ & $0.0 \%$ & $0.0 \%$ & $0.0 \%$ & $2.0 \%$ & $1.7 \%$ & $0.0 \%$ & $0.3 \%$ & $0.0 \%$ & $0.0 \%$ & $4.3 \%$ \\
\hline & \multirow{4}{*}{ 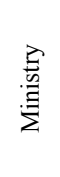 } & Number & 0 & 0 & 0 & 0 & 0 & 9 & 1 & 0 & 0 & 0 & 0 & 10 \\
\hline & & Source $(\%)$ & $0.0 \%$ & $0.0 \%$ & $0.0 \%$ & $0.0 \%$ & $0.0 \%$ & $90.0 \%$ & $10.0 \%$ & $0.0 \%$ & $0.0 \%$ & $0.0 \%$ & $0.0 \%$ & $100.0 \%$ \\
\hline & & Quality (\%) & $0.0 \%$ & $0.0 \%$ & $0.0 \%$ & $0.0 \%$ & $0.0 \%$ & $7.3 \%$ & $10.0 \%$ & $0.0 \%$ & $0.0 \%$ & $0.0 \%$ & $0.0 \%$ & $2.8 \%$ \\
\hline & & Total (\%) & $0.0 \%$ & $0.0 \%$ & $0.0 \%$ & $0.0 \%$ & $0.0 \%$ & $2.6 \%$ & $0.3 \%$ & $0.0 \%$ & $0.0 \%$ & $0.0 \%$ & $0.0 \%$ & $2.8 \%$ \\
\hline & \multirow{4}{*}{$\begin{array}{l}\stackrel{0}{0} \\
: 0 \\
0\end{array}$} & Number & 7 & 1 & 0 & 0 & 0 & 2 & 1 & 0 & 0 & 0 & 0 & 11 \\
\hline & & Source $(\%)$ & $63.6 \%$ & $9.1 \%$ & $0.0 \%$ & $0.0 \%$ & $0.0 \%$ & $18.2 \%$ & $9.1 \%$ & $0.0 \%$ & $0.0 \%$ & $0.0 \%$ & $0.0 \%$ & $100.0 \%$ \\
\hline & & Quality (\%) & $3.7 \%$ & $12.5 \%$ & $0.0 \%$ & $0.0 \%$ & $0.0 \%$ & $1.6 \%$ & $10.0 \%$ & $0.0 \%$ & $0.0 \%$ & $0.0 \%$ & $0.0 \%$ & $3.1 \%$ \\
\hline & & Total (\%) & $2.0 \%$ & $0.3 \%$ & $0.0 \%$ & $0.0 \%$ & $0.0 \%$ & $0.6 \%$ & $0.3 \%$ & $0.0 \%$ & $0.0 \%$ & $0.0 \%$ & $0.0 \%$ & $3.1 \%$ \\
\hline & \multirow{4}{*}{ 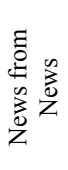 } & Number & 5 & 0 & 0 & 1 & 0 & 4 & 0 & 0 & 0 & 0 & 1 & 11 \\
\hline & & Source $(\%)$ & $45.5 \%$ & $0.0 \%$ & $0.0 \%$ & $9.1 \%$ & $0.0 \%$ & $36.4 \%$ & $0.0 \%$ & $0.0 \%$ & $0.0 \%$ & $0.0 \%$ & $9.1 \%$ & $100.0 \%$ \\
\hline & & Quality (\%) & $2.7 \%$ & $0.0 \%$ & $0.0 \%$ & $12.5 \%$ & $0.0 \%$ & $3.2 \%$ & $0.0 \%$ & $0.0 \%$ & $0.0 \%$ & $0.0 \%$ & $50.0 \%$ & $3.1 \%$ \\
\hline & & Total (\%) & $1.4 \%$ & $0.0 \%$ & $0.0 \%$ & $0.3 \%$ & $0.0 \%$ & $1.1 \%$ & $0.0 \%$ & $0.0 \%$ & $0.0 \%$ & $0.0 \%$ & $0.3 \%$ & $3.1 \%$ \\
\hline
\end{tabular}


(Table 16 to be continued)

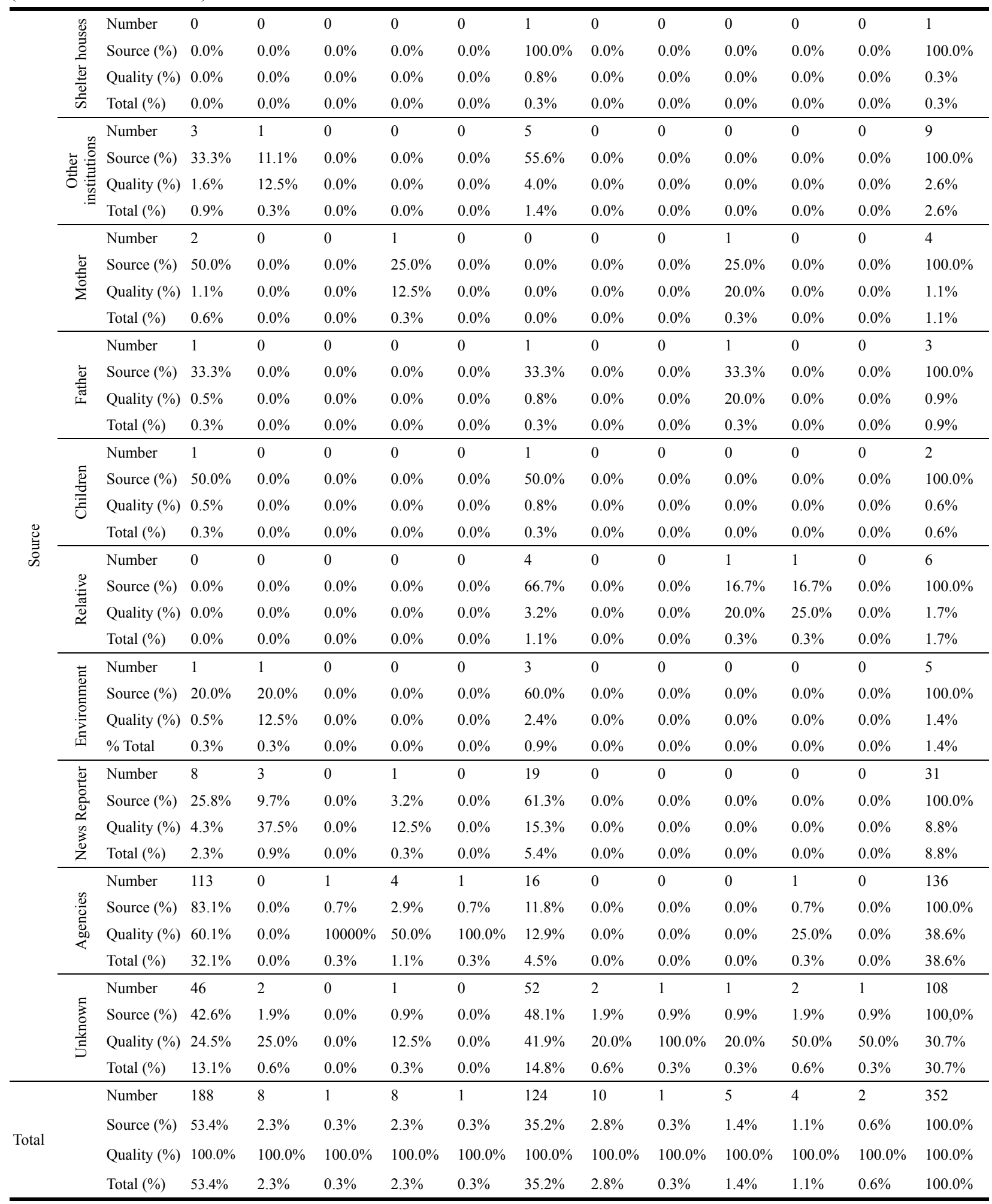

Null hypothesis claiming that there is no relationship between the source and the quality is rejected. As it can be seen in Table 17, when the source of the news and the quality of the news are compared, $\mathrm{H}_{0}$ is rejected 
based on the values $X^{2}=304.797$ and $p<0.05$. Therefore, it is concluded that there is a statistically significant relationship between these two variables.

Table 17

Chi-Square Test Between the Source and the Quality of the News $(N=352)$

\begin{tabular}{llll}
\hline Source and quality & Value & $S D$ & $p$-value \\
\hline Pearson Chi-square & 304.797 & 130 & 0.000 \\
\hline
\end{tabular}

The correlation between the source and the quality is statistically significant $(p=0.000)$ and there is a negative but weak relationship between the source of the news and the quality of the news (see Table 18). The source of the news can explain the quality at the rate of $25 \%(r=-0.252)$. It can be stated that as the number of the sources increases, the quality deteriorates, or vice versa.

Table 18

Correlational Relationship Between the Source and the Quality of the News

\begin{tabular}{lcc}
\hline & Source & Quality \\
\hline Source & 1.00 & $-0.252^{* *}$ \\
Quality & $-0.252^{* *}$ & 1.00 \\
\hline
\end{tabular}

Notes. ${ }^{*} p<0.05 ;{ }^{* *} p<0.01$.

In a general sense, there is not any relationship between the location of the news and violence. However, when their subcategories are analyzed, it is possible to reach some general implications.

As it can be seen in Table 19, different locations of the news can change according to different violence types. The percentages of the sub-categories defined in the location of the news are such: middle (32.4\%), underside $(22.2 \%)$, upperside $(20.2 \%)$, other $(13.1 \%)$, headline $(9.1 \%)$, and subheading $(3.1 \%)$. Percentages related to violence type are such: physical $(79.8 \%)$, none (6.5\%), other $(5.4 \%)$, sexual $(4.8 \%)$, psychological (28\%), and legal $(0.6 \%)$. Based on this, when the sub-categories are examined, it can be stated that physical violence is included mostly in the news in the middle part (2.4\%), than in the news at underside (17.9\%), upperside (16.5\%), other (9.7\%), and heading (8.5\%), respectively. While the category of "none" is given place, though little, in the news in the middle, underside, and upperside $(2.6 \%, 2.3 \%$, and $1.1 \%$, respectively), this kind of news is not given any place in headings or subheadings. When the type "other" is analyzed, the first location for the news is "other" (2.3\%). Psychological violence is given place in the middle part (2.0\%). Other details can be seen in Table 19 .

Table 19

Contingency Table for the Location of the News and the Violence

\begin{tabular}{|c|c|c|c|c|c|c|c|c|c|}
\hline & & & \multicolumn{6}{|c|}{ Violence } & \multirow{2}{*}{ Total } \\
\hline & & & Legal & Sexual & Psychological & Physical & None & Other & \\
\hline \multirow{8}{*}{ 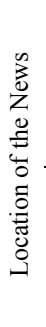 } & \multirow{4}{*}{ Subheading } & Number & 0 & 0 & 0 & 10 & 0 & 1 & 11 \\
\hline & & Location of news (\%) & $0.0 \%$ & $0.0 \%$ & $0.0 \%$ & $90.9 \%$ & $0.0 \%$ & $9.1 \%$ & $100.0 \%$ \\
\hline & & Violence (\%) & $0.0 \%$ & $0.0 \%$ & $0.0 \%$ & $3.6 \%$ & $0.0 \%$ & $5.3 \%$ & $3.1 \%$ \\
\hline & & Total (\%) & $0.0 \%$ & $0.0 \%$ & $0.0 \%$ & $2.8 \%$ & $0.0 \%$ & $0.3 \%$ & $3.1 \%$ \\
\hline & \multirow{4}{*}{ Heading } & Number & 1 & 0 & 0 & 30 & 0 & 1 & 32 \\
\hline & & Location of news $(\%)$ & $3.1 \%$ & $0.0 \%$ & $0.0 \%$ & $93.8 \%$ & $0.0 \%$ & $3.1 \%$ & $100.0 \%$ \\
\hline & & Violence $(\%)$ & $50.0 \%$ & $0.0 \%$ & $0.0 \%$ & $10.7 \%$ & $0.0 \%$ & $5.3 \%$ & $9.1 \%$ \\
\hline & & Total $(\%)$ & $0.3 \%$ & $0.0 \%$ & $0.0 \%$ & $8.5 \%$ & $0.0 \%$ & $0.3 \%$ & $9.1 \%$ \\
\hline
\end{tabular}


(Table 19 to be continued)

\begin{tabular}{|c|c|c|c|c|c|c|c|c|}
\hline & Number & 0 & 4 & 1 & 58 & 4 & 4 & 71 \\
\hline \multirow{3}{*}{ Upperside } & Location of news $(\%)$ & $0.0 \%$ & $5.6 \%$ & $1.4 \%$ & $81.7 \%$ & $5.6 \%$ & $5.6 \%$ & $100.0 \%$ \\
\hline & Violence $(\%)$ & $0.0 \%$ & $23.5 \%$ & $10.0 \%$ & $20.6 \%$ & $17.4 \%$ & $21.1 \%$ & $20.2 \%$ \\
\hline & Total $(\%)$ & $0.0 \%$ & $1.1 \%$ & $0.3 \%$ & $16.5 \%$ & $1.1 \%$ & $1.1 \%$ & $20.2 \%$ \\
\hline \multirow{4}{*}{ Underside } & Number & 1 & 2 & 1 & 63 & 8 & 3 & 78 \\
\hline & Location of news (\%) & $1.3 \%$ & $2.6 \%$ & $1.3 \%$ & $80.8 \%$ & $10.3 \%$ & $3.8 \%$ & $100.0 \%$ \\
\hline & Violence (\%) & $50.0 \%$ & $11.8 \%$ & $10.0 \%$ & $22.4 \%$ & $34.8 \%$ & $15.8 \%$ & $22.2 \%$ \\
\hline & Total $(\%)$ & $0.3 \%$ & $0.6 \%$ & $0.3 \%$ & $17.9 \%$ & $2.3 \%$ & $0.9 \%$ & $22.2 \%$ \\
\hline \multirow{4}{*}{ Middle } & Number & 0 & 10 & 7 & 86 & 9 & 2 & 114 \\
\hline & Location of news $(\%)$ & $0.0 \%$ & $8.8 \%$ & $6.1 \%$ & $75.4 \%$ & $7.9 \%$ & $1.8 \%$ & $100.0 \%$ \\
\hline & Violence (\%) & $0.0 \%$ & $58.8 \%$ & $70.0 \%$ & $30.6 \%$ & $39.1 \%$ & $10.5 \%$ & $32.4 \%$ \\
\hline & Total $(\%)$ & $0.0 \%$ & $2.8 \%$ & $2.0 \%$ & $24.4 \%$ & $2.6 \%$ & $0.6 \%$ & $32.4 \%$ \\
\hline \multirow{4}{*}{ Other } & Number & 0 & 1 & 1 & 34 & 2 & 8 & 46 \\
\hline & Location of news $(\%)$ & $0.0 \%$ & $2.2 \%$ & $2.2 \%$ & $73.9 \%$ & $4.3 \%$ & $17.4 \%$ & $100.0 \%$ \\
\hline & Violence (\%) & $0.0 \%$ & $5.9 \%$ & $10.0 \%$ & $12.1 \%$ & $8.7 \%$ & $42.1 \%$ & $13.1 \%$ \\
\hline & Total (\%) & $0.0 \%$ & $0.3 \%$ & $0.3 \%$ & $9.7 \%$ & $0.6 \%$ & $2.3 \%$ & $13.1 \%$ \\
\hline \multirow{4}{*}{ Total } & Number & 2 & 17 & 10 & 281 & 23 & 19 & 352 \\
\hline & Location of news (\%) & $0.6 \%$ & $4.8 \%$ & $2.8 \%$ & $79.8 \%$ & $6.5 \%$ & $5.4 \%$ & $100.0 \%$ \\
\hline & Violence (\%) & $100.0 \%$ & $100.0 \%$ & $100.0 \%$ & $100.0 \%$ & $100.0 \%$ & $100.0 \%$ & $100.0 \%$ \\
\hline & Total (\%) & $0.6 \%$ & $4.8 \%$ & $2.8 \%$ & $79.8 \%$ & $6.5 \%$ & $5.4 \%$ & $100.0 \%$ \\
\hline
\end{tabular}

Table 20

Correlational Relationship Between the Location of the News and the Type of the News

\begin{tabular}{lcc}
\hline & News location & News type \\
\hline News location & 1.00 & $-0.187^{* *}$ \\
News type & $-0.187^{* *}$ & 1.00 \\
\hline
\end{tabular}

Notes. ${ }^{*} p<0.05 ;{ }^{* *} p<0.01$.

Null hypothesis claiming that there is no relationship between the location and the type of the news is rejected (see Table 20). As it can be seen in Table 21, when the location of the news and the type of the news are compared, $\mathrm{H}_{0}$ is rejected based on the values $X^{2}=34.565$ and $p<0.05$. Therefore, it is concluded that there is a statistically significant relationship between these two variables.

Table 21

Chi-Square Test Between the Location of the News and the Type of the News $(N=352)$

\begin{tabular}{llll}
\hline News location and news type & Value & $S D$ & $p$-value \\
\hline Pearson Chi-square & 34.565 & 5 & 0.000 \\
\hline
\end{tabular}

According to Chi-square test, there is a relationship between the location of the news and the type of the news. As it can be seen in Table 22, different locations of the news refer to differences in the type of the news. The categories with the highest percentages related to the location of news are: middle (32.4\%), underside (22.2\%), upperside $(20.2 \%)$, other $(131 \%)$, heading $(9.1 \%)$, and subheading $(3.1 \%)$. The distribution of the percentages of the types of the news is text (42\%) and mixed (58\%). Text-type news at the underside has the highest percentage with $13.4 \%$. Text-type news in the middle has the second highest percentage with $12.2 \%$. The percentages of the text-type news in upperside, other parts, heading, and subheading are sorted: $8.0 \%$, $7.4 \%, 0.9 \%$, and $0.3 \%$, respectively. The percentages of the mixed-type news according to their locations are 
listed as: middle $(20.2 \%)$, upperside $(12.2 \%)$, underside $(8.8 \%)$, heading $(8.2 \%)$, other $(5.7 \%)$, and subheading $(2.8 \%)$. In this sense, it can be seen that mixed type news is preferred mostly in the middle and upperside.

Table 22

Contingency Table Between the Location of the News and the Type of the News

\begin{tabular}{|c|c|c|c|c|c|}
\hline & & & \multicolumn{2}{|c|}{ Type of the news } & \multirow{2}{*}{-Total } \\
\hline & & & Text & Mixed & \\
\hline \multirow{24}{*}{ News location } & \multirow{4}{*}{ Sub-heading } & Number & 1 & 10 & 11 \\
\hline & & News location $(\%)$ & $9.1 \%$ & $90.9 \%$ & $100.0 \%$ \\
\hline & & News type $(\%)$ & $0.7 \%$ & $4.9 \%$ & $3.1 \%$ \\
\hline & & Total $(\%)$ & $0.3 \%$ & $2.8 \%$ & $3.1 \%$ \\
\hline & \multirow{4}{*}{ Heading } & Number & 3 & 29 & 32 \\
\hline & & News location $(\%)$ & $9.4 \%$ & $90.6 \%$ & $100.0 \%$ \\
\hline & & News type $(\%)$ & $2.0 \%$ & $14.2 \%$ & $9.1 \%$ \\
\hline & & Total (\%) & $0.9 \%$ & $8.2 \%$ & $9.1 \%$ \\
\hline & \multirow{4}{*}{ Upperside } & Number & 28 & 43 & 71 \\
\hline & & News location $(\%)$ & $39.4 \%$ & $60.6 \%$ & $100.0 \%$ \\
\hline & & News type (\%) & $18.9 \%$ & $21.1 \%$ & $20.2 \%$ \\
\hline & & Total $(\%)$ & $8.0 \%$ & $12.2 \%$ & $20.2 \%$ \\
\hline & \multirow{4}{*}{ Underside } & Number & 47 & 31 & 78 \\
\hline & & News location (\%) & $60.3 \%$ & $39.7 \%$ & $100.0 \%$ \\
\hline & & News type (\%) & $31.8 \%$ & $15.2 \%$ & $22.2 \%$ \\
\hline & & Total $(\%)$ & $13.4 \%$ & $8.8 \%$ & $22.2 \%$ \\
\hline & \multirow{4}{*}{ Middle } & Number & 43 & 71 & 114 \\
\hline & & News location (\%) & $37.7 \%$ & $62.3 \%$ & $100.0 \%$ \\
\hline & & News type $(\%)$ & $29.1 \%$ & $34.8 \%$ & $32.4 \%$ \\
\hline & & Total $(\%)$ & $12.2 \%$ & $20.2 \%$ & $32.4 \%$ \\
\hline & \multirow{4}{*}{ Other } & Number & 26 & 20 & 46 \\
\hline & & News location $(\%)$ & $56.5 \%$ & $43.5 \%$ & $100.0 \%$ \\
\hline & & News type $(\%)$ & $17.6 \%$ & $9.8 \%$ & $13.1 \%$ \\
\hline & & Total $(\%)$ & $7.4 \%$ & $5.7 \%$ & $13.1 \%$ \\
\hline \multirow{4}{*}{ Total } & & Number & 148 & 204 & 352 \\
\hline & & News location $(\%)$ & $42.0 \%$ & $58.0 \%$ & $100.0 \%$ \\
\hline & & News type $(\%)$ & $100.0 \%$ & $100.0 \%$ & $100.0 \%$ \\
\hline & & Total (\%) & $42.0 \%$ & $58.0 \%$ & $100.0 \%$ \\
\hline
\end{tabular}

There is not any relationship between the newspaper and the type of the news. Some conclusions can be reached from the percentages of the news which the newspapers report according to the type of violence.

Milliyet newspaper has the highest percentage of violence news (19.3\%). Türkiye newspaper follows it with 14.2\%. The percentages of other newspapers are as in the following: Hürriyet (12.5\%), Posta (11.1\%), Bugün (10.5\%), Sabah (9.1\%), Haber Türk (8.5\%), Sözcü (7.7\%), and Zaman (7.1\%). Milliyet has the highest percentage of physical violence (14.5\%). Milliyet and Hürriyet have the highest rate of sexual violence news $(2.3 \%$ and $2.0 \%)$. Other data can be examined in Table 23.

The correlation between the headline and the writer is statistically significant $(p=0.000)$ and there is a positive relationship between these two variables. The headline can be explained by the writer at the rate of $30 \%$ $(r=0.298)$ (see Table 24). 
Table 23

Table of Contingency Between the Newspaper and the Violence Type

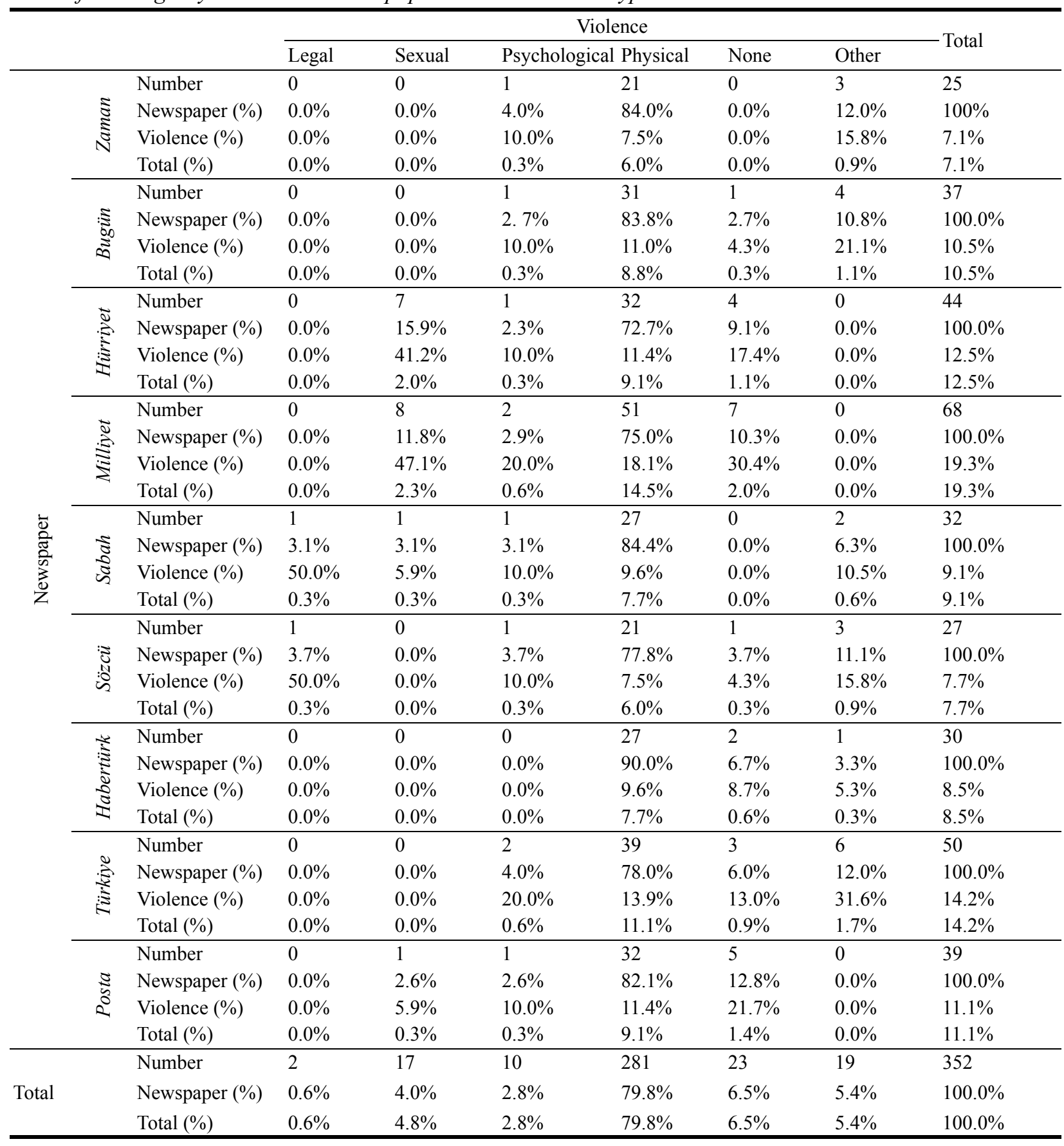

Table 24

Correlational Relationship Between Headline and the Writer

\begin{tabular}{lll}
\hline & Headline & Writer \\
\hline Headline & 1.00 & $0.298^{* *}$ \\
Writer & $0.298^{* *}$ & 1.00 \\
\hline
\end{tabular}

Notes. ${ }^{*} p<0.05 ;{ }^{* *} p<0.01$. 
Null hypothesis claiming that there is no relationship between headline and the type of writer is rejected. As it can be seen in Table 25, when headline and the type of writer are compared, $\mathrm{H}_{0}$ is rejected based on the values $X^{2}=59.961$ and $p<0.05$. Therefore, it is concluded that there is a statistically significant relationship between these two variables.

Table 25

Chi-Square Test Between Headline and Writer $(N=352)$

\begin{tabular}{llll}
\hline Headline and writer type & Value & $S D$ & $p$-value \\
\hline Pearson Chi-square & 59.961 & 21 & 0.000 \\
\hline
\end{tabular}

According to Chi-square test, there is a relationship between headline and columnist type. The percentages of this relationship are presented for different sub-categories. As it can be seen in Table 26, different headlines refer to differences in columnist type. Percentages according to type of headline are: neutral (47.2\%), negative (32.4\%), and positive (20.5\%). Percentages related to writer are as following: reporter (46.9\%), other (43.8), columnist (5.4\%), and practitioner specialist (1.7\%). Besides, all other values can be acquired from Table 26 . Reporters' positive headlines have $15.9 \%$. The rate of positive headlines is $2.0 \%$ for columnist and $2.6 \%$ for other writers. For negative headlines, the category of "other writers" (15.9\%) has a higher percentage than the category of "reporters" (14.8\%). There is a similar rate for neutral headlines. The category of "other writers" has a percentage of $25.3 \%$, the category of "reporters" has $16.2 \%$, and the category of "columnist" has $2.8 \%$. All other rates can be inferred from Table 26.

Table 26

Table of Contingency between Headline and Writer

\begin{tabular}{|c|c|c|c|c|c|c|c|c|c|c|c|}
\hline & & & \multicolumn{8}{|c|}{ Writer } & \multirow[b]{2}{*}{ Total } \\
\hline & & & Columnist & Scientist & Reporter & $\begin{array}{l}\text { CSO } \\
\text { attendant }\end{array}$ & Lawyer & $\begin{array}{l}\text { Practitioner } \\
\text { specialist }\end{array}$ & Himself & Other & \\
\hline \multirow{12}{*}{ 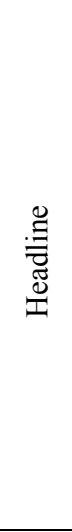 } & \multirow{4}{*}{ 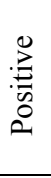 } & Number & 7 & 0 & 56 & 0 & 0 & 0 & 0 & 9 & 72 \\
\hline & & Headline (\%) & $9.7 \%$ & $0.0 \%$ & $77.8 \%$ & $0.0 \%$ & $0.0 \%$ & $0.0 \%$ & $0.0 \%$ & $12.5 \%$ & $100 \%$ \\
\hline & & Writer (\%) & $36.8 \%$ & $0.0 \%$ & $33.9 \%$ & $0.0 \%$ & $0.0 \%$ & $0.0 \%$ & $0.0 \%$ & $5.8 \%$ & $20.5 \%$ \\
\hline & & Total (\%) & $2.0 \%$ & $0.0 \%$ & $15.9 \%$ & $0.0 \%$ & $0.0 \%$ & $0.0 \%$ & $0.0 \%$ & $2.6 \%$ & $20.5 \%$ \\
\hline & \multirow{4}{*}{ 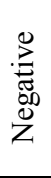 } & Number & 2 & 0 & 52 & 0 & 1 & 3 & 0 & 56 & 114 \\
\hline & & Headline (\%) & $1.8 \%$ & $0.0 \%$ & $45.6 \%$ & $0.0 \%$ & $0.9 \%$ & $2.6 \%$ & $0.0 \%$ & $49.1 \%$ & $100 \%$ \\
\hline & & Writer (\%) & $10.5 \%$ & $0.0 \%$ & $31.5 \%$ & $0.0 \%$ & $33.3 \%$ & $50.0 \%$ & $0.0 \%$ & $36.4 \%$ & $32.4 \%$ \\
\hline & & Total (\%) & $0.6 \%$ & $0.0 \%$ & $14.8 \%$ & $0.0 \%$ & $0.3 \%$ & $0.9 \%$ & $0.0 \%$ & $15.9 \%$ & $32.4 \%$ \\
\hline & \multirow{4}{*}{$\begin{array}{l}\bar{\pi} \\
\text { 节 } \\
\ddot{Z}\end{array}$} & Number & 10 & 1 & 57 & 2 & 2 & 3 & 2 & 89 & 166 \\
\hline & & Headline (\%) & $6.0 \%$ & $0.6 \%$ & $34.3 \%$ & $1.2 \%$ & $1.2 \%$ & $1.8 \%$ & $1.2 \%$ & $53.6 \%$ & $100 \%$ \\
\hline & & Writer (\%) & $52.6 \%$ & $100 \%$ & $34.5 \%$ & $100 \%$ & $66.7 \%$ & $50.0 \%$ & $100 \%$ & $57.8 \%$ & $47.2 \%$ \\
\hline & & Total (\%) & $2.8 \%$ & $0.3 \%$ & $16.2 \%$ & $0.6 \%$ & $0.6 \%$ & $0.9 \%$ & $0.6 \%$ & $25.3 \%$ & $47.2 \%$ \\
\hline \multirow{3}{*}{ Total } & & Number & 19 & 1 & 165 & 2 & 3 & 6 & 2 & 154 & 352 \\
\hline & & Headline (\%) & $5.4 \%$ & $0.3 \%$ & $46.9 \%$ & $0.6 \%$ & $0.9 \%$ & $1.7 \%$ & $0.6 \%$ & $43.8 \%$ & $100 \%$ \\
\hline & & Total (\%) & $5.4 \%$ & $0.3 \%$ & $46.9 \%$ & $0.6 \%$ & $0.9 \%$ & $1.7 \%$ & $0.6 \%$ & $43.8 \%$ & $100 \%$ \\
\hline
\end{tabular}

\section{Conslusion and Suggestions}

In this study, Turkey's most prevalent nine newspapers with the highest circulations (Zaman, Posta, Hürriyet, Sözcü, Sabah, Haber Türk, Türkiye, Bugün, and Milliyet) have been analyzed with the content analysis between December 4, 2014 and December 5, 2014 for a month. The qualities of the articles on domestic violence, 
writing style, sources, writers, location of the news, the way they approach to the child, and the relationship between the content and the location have been analyzed. Following results have been obtained:

A total of 352 newspapers articles related to domestic violence were published for a month.

There is a weak, positive, and statistically significant relationship between violence and reasons of violence $(p=0.006)$. Reason of the violence can explain $15 \%$ of the violence $(r=0.148)$. As the reasons of violence increase, the violence also increases, though weakly.

According to Chi-square test, conducted to examine whether there is differentiation in the quality of the articles according to source, there is a relationship between quality and source. The percentages of this relationship are presented. As it can be seen in Table 16, different types of source can change according to different qualities. The highest percentages in quality are respectively presented as following: explanation (53.4\%), informing (35.2\%), comment (2.8\%), and criticize and support (2.3\%).

There is no relationship between the location of the news and the violence. However, it is possible to reach general implications when sub-categories are analyzed.

There is no statistically significant relationship between location of the news and type of the news. The reason behind this can be the fact that some types of the news were presented in similar pages. For example, murder news may be expected to be written on third pages by the reader, but newspapers' printing and typesetting differences weaken this relationship.

According to analysis conducted to examine whether the type of the news has an effect on presenting the news on the headline, it has been found that it has an effect in the rate of $9.1 \% .0 .9 \%$ of this effect belongs to text-type news and $8.2 \%$ belongs to mixed-type news. This effect is led by the fact that the news was made in mixed-type

When the relationship between the newspapers and type of violence was examined, no statistically significant correlation was found. However, some conclusions can be referred from the percentages of the news which newspapers reported according to type of violence. Newspapers work with some news agencies and can report similar news. Therefore, it can be concluded that there is no specific kind of news related to domestic violence for each newspaper.

The correlation between headline and type of the writer is statistically significant $(p=0.000)$. There is a positive medium-level correlation between the headline and the writer. Headline can be explained by the writer in the rate of $30 \%(r=0.298)$.

The null hypothesis claiming that there is no relationship between headline and writer is rejected. As it can be seen in Table 25, when headline and type of the writer are compared, $\mathrm{H}_{0}$ is rejected with $X^{2}=59.961$ and $p<0.05$ and it is concluded that there is a relationship. Therefore, it can be stated that writers write in the field in which they are working and find headlines suitable to this field.

In the studies, which will be conducted based on the findings of this study, reporting style of the news related to domestic violence, their language, frequency, source, and type should be investigated at intervals. In accordance with the principles of printed media, to what extent the rights of victims of domestic violence are protected can be investigated.

\section{References}

Ayan, S. (2007). Aile içinde şiddete uğrayan çocukların saldırganlık eğilimleri (Aggressiveness tendencies of the children exposed to domestic violence). Anatolian Journal of Psychiatry, 8, 206-214. (in Turkish) 
Hartmann, A. L. (2002). Wieder das schweigen und vergessen (Again silence and forgetness). In Gewalt in der familie: Sozialwissenschaftiche erkenntnisse und praktisch —theologische reflexionen (Violence in the family, social sciences awareness and pratical-Theology reflection). (in Turkish)

Kaymak, Ö. (2004). Aile içinde Öfke ve Saldırganlığın Yansımaları (The reflections of anger and aggression in family). Ankara Üniversitesi Eğitim Bilimleri Fakültesi Dergisi, 37(2), 27-39. (in Turkish)

Martinius, J. (1989). Personality development in abused children. In L. Retzlaff (Ed.), Violence toards children. Abuse and sexual abuse towards minor child (pp. 92-99). Neckarsulm. (in Turkish)

Mertens, B., \& Pankofer, S. (2011). Child abuse. Physical Violence in Family, S, 15. (in Turkish)

Republic of Turkey. (2008). General directorate for women status, national and international legal regulations for domestic violence against women (The Project of Fight With Domestic Violence Against Women).

Steck, M., \& Cizek, B. (2010). Siblings abuse, violence towards children. In Federal Ministry for Economy, Family, and Youths Section Family and Youth Department. (in Turkish)

T. C. Prime Ministry. (2008). General manager of women's status, national and international legal arrangement about domestic violence to woman (The Struggle Project With Domestic Violence Towards Woman). (in Turkish)

Turkish Association of Journalists (TAJ). (2014). Publication principles. Retrieved June 6, 2014, from http://www.tgc.org.tr/bildirge.asp

Turkey Statistics Institution (TÜİK). (2008). The rate of divorce according to regional units. Retrieved June 15, 2014, from http://www.tuik.gov.tr/PreTablo.do?alt_id=1068

Yıldırım, A. \& Şimsek, H. (2011). Sosyal bilimlerde nitel araştırma yöntemleri (Qualitative research methods in the social sciences) (8th ed.). Ankara: Seçkin Yayıncılık. (in Turkish) 